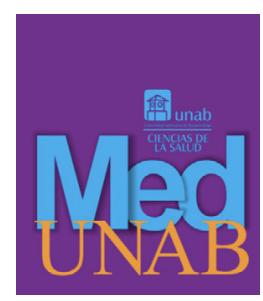

REVISTA DE LA FACULTAD

DE CIENCIAS DE LA SALUD

Vol. 24(2): 151-154, agosto - noviembre 2021

i-SSN $0123-7047$

e-ISSN 2382-4603

DOI: https://doi.org/10.29375/01237047.4195

\title{
Ivermectina un medicamento de uso indiscriminado en el manejo del Covid-19
}

Ivermectin a drug of indiscriminate use in the management of Covid-19

Ivermectina, uma droga de uso indiscriminado no manejo da Covid-19

Los Coronaviridae son una familia de virus ARN que han afectado, a lo largo de la historia, a mamíferos y aves. Estos patógenos, conocidos y estudiados por varias décadas, también han sido los responsables de infecciones que usualmente se presentan en el tracto respiratorio en humanos. Su más reciente variante SARSCoV-2, fue identificada a finales del año 2019 en la ciudad china de Wuhan donde el virus fue identificado como el causante de múltiples neumonías severas en la población (1).

Dicho brote tuvo una extensión que superó las expectativas, creando el hito más grande del siglo XXI. El 11 de marzo de 2020 el virus fue declarado pandemia, su transmisión de forma directa de persona a persona jugó un papel muy importante en el rápido esparcimiento de este nuevo coronavirus. Su gran abanico de presentación clínica, que parte desde formas completamente asintomáticas hasta llegar a infecciones de tracto respiratorio más graves e incluso mortales, jamás antes vistas (2), se convirtió en un reto social, político y médico.

La atención inicial de los pacientes infectados derivó de consensos de expertos, debido a la escasa evidencia científica publicada en el momento. Algunos de los medicamentos utilizados empíricamente obtuvieron mejores desenlaces que otros y, por ende, empezaron a ser estudiados con mayor rigor científico. Uno de los fármacos que más ha sido nombrado es la ivermectina, un derivado del 22,23-dihidro de la avermectina B1 de lactona macrocíclica, que es a su vez producida por la bacteria Streptomyces avermitillis (3). Este medicamento presenta una gran afinidad selectiva y actividad inhibitoria contra múltiples proteínas y enzimas, su mecanismo de acción antiviral se cree que se da a través de la inhibición selectiva de importación nuclear de las proteínas virales, la cual es mediada por importinas, la proteína IMP $\alpha / \beta 1$ (4).

La ivermectina, ampliamente conocida y utilizada como antihelmíntico en varios países del mundo incluyendo Colombia, se encuentra indicada en el tratamiento de escabiosis, pediculosis, dermodecidosis, en los casos de filariasis linfática y como tratamiento alternativo de la estrongiloidiasis. La presentación autorizada en el país es de uso oral, en una concentración de $6 \mathrm{mg} / \mathrm{mL}$ y en cápsulas de $3 \mathrm{mg}$, las dosis utilizadas son entre $150 \mathrm{mcg} /$ 
$\mathrm{kg}$ y $200 \mathrm{mcg} / \mathrm{kg}$ de peso, variando de acuerdo con la indicación (5).

A este medicamento, con más de 40 años de uso en humanos y con una alta seguridad en las dosis previamente estudiadas, le fueron reconocidas nuevas propiedades in vitro en la inhibición de la replicación del SARS-CoV-2 (6).

Los primeros experimentos reportados in vitro sobre su acción contra el SARS-CoV-2 fueron realizados en un cultivo celular infectado con el virus al cual se le agregó ivermectina. Se usaron concentraciones de 2.8 y 5 micromolar, logrando reducir la replicación viral entre un $50 \%$ y $90 \%$ respectivamente. Según los resultados de esta investigación la ivermectina tiene la capacidad de modular la respuesta inmune exacerbada producida por el SARS-CoV-2, gracias a la lipofilicidad que presenta, la cual logra acumularse en compartimientos profundos, como los pulmones (7).

Posterior a este experimento iniciaron ensayos clínicos alrededor del uso de la ivermectina en pacientes infectados por SARS-CoV-2, algunos más relevantes que otros, que aparecieron durante el 2020. Un ensayo clínico realizado denominado ICON incluyó 280 pacientes, de los cuales 173 fueron tratados con ivermectina y 107 sin ivermectina. Este estudio reportó una menor mortalidad en el grupo de ivermectina (15.0\% frente a $25.2 \%$; OR, 0.52; IC del 95\%, 0.29-0.96; $\mathrm{P}=0.03$ ), además de una disminución en la mortalidad en el grupo de pacientes tratados con ivermectina con una presentación grave de la enfermedad $(38.8 \%$ frente a $80.7 \%$; OR, 0.15; IC del 95\%, 0.05-0.47; p $=0.001)$. Sin embargo en este estudio cabe resaltar que todos los pacientes tenían como manejo de base hidroxicloroquina, azitromicina o, en algunos casos, ambos medicamentos (8).

El estudio ICON ha sido altamente criticado, dentro de las alertas que emergen de este manuscrito algunas se relacionan con las variables que no fueron tomadas en cuenta en el contexto del ensayo, una de las más importantes es el desconocimiento de la etapa del virus en cada paciente, es decir, que no es claro el momento de aparición de los síntomas y su correspondencia con la admisión en el servicio de hospitalización y el inicio de la medicación (9).

En un estudio realizado en Bangladesh, con pacientes hospitalizados por SARS-CoV-2, se eligieron 72 pacientes divididos en tres grupos: ivermectina oral sola (12 mg una vez al día por 5 días), ivermectina oral en combinación con doxiciclina (12 mg de ivermectina en dosis única y $200 \mathrm{mg}$ doxiciclina el día 1 , seguido de 100 $\mathrm{mg}$ cada $12 \mathrm{~h}$ durante los 4 días siguientes) y un grupo de control con placebo. Como desenlace se evidenció la reducción de la progresión de la enfermedad en comparación con el placebo, los pacientes presentaron mejoría de los índices de oxigenación, así como la disminución de marcadores pronósticos como LDH y PCR. Además, se registraron signos de disminución de carga viral indirecta y replicación del virus mediante la disminución del ácido nucleico viral al séptimo día de padecer la enfermedad (10).

Tal vez uno de los estudios más grandes realizados hasta el momento fue un metaanálisis en el que se incluyeron cuatro trabajos para una totalidad de 629 pacientes elegidos e infectados con SARS-CoV-2, catalogados con enfermedad leve o moderada. Las dosis empleadas de ivermectina fueron entre $0.15-0.2 \mathrm{mg} / \mathrm{kg}$ en conjunto con la medicación habitual. Los hallazgos encontrados fueron positivos, lo que llevó a considerar que la ivermectina contribuía a la mejoría clínica de los pacientes. Sin embargo, los mismos autores advirtieron que la calidad del estudio fue baja (11).

Este fármaco, como lo vimos antes, no solamente tuvo un auge en el tratamiento sino también a manera de profilaxis. Un estudio de casos y controles realizado en la India emparejó 186 pares de casos y controles, la población estudiada correspondió a trabajadores del área de la salud que dieron positivo y negativo, respectivamente, para COVID-19 por RT-PCR. La exposición fue definida como la ingesta de ivermectina, hidroxicloroquina, vitamina-C u otras profilaxis para COVID-19. En total fueron 76 controles y 41 casos tomaron profilaxis con ivermectina. Las dosis utilizadas de ivermectina fueron de $300 \mu \mathrm{g} / \mathrm{kg}$ de peso corporal el día 1 y día 4 , logrando una reducción del $73 \%$ de SARSCoV-2 entre los trabajadores de la salud durante el mes siguiente (12).

Colombia no se queda atrás en los estudios sobre este medicamento, en la ciudad Cali fue realizado un ensayo clínico aleatorizado de grupos paralelos, doble ciego controlado con placebo. Los pacientes incluidos en el estudio fueron adultos con enfermedad leve y síntomas menores a siete días, la dosis indicada fue de $300 \mathrm{mcg} /$ $\mathrm{kg}$ vía oral por día. Se asignaron 200 pacientes al medicamento y 200 al placebo. Los resultados abordaron que el tiempo hasta la resolución de los síntomas fue de 10 días (IQR, 9-13) en el grupo de ivermectina en comparación con 12 días (IQR, 9-13) en el grupo de placebo. Para el día 21 el $82 \%$ en el grupo de ivermectina y el $79 \%$ en el grupo de placebo habían resuelto los síntomas. A pesar de esto, los autores concluyen que en 
los adultos con COVID-19 leve un ciclo de 5 días de ivermectina, en comparación con placebo, no mejoró significativamente el tiempo hasta la resolución de los síntomas, dando la recomendación de la necesidad de ensayos más grandes para comprender los efectos de la ivermectina en otros resultados clínicamente relevantes (13).

Pese a los exhaustivos estudios para el conocimiento del SARS-CoV-2 y sus diversos tratamientos, aún no existe una protocolo estandarizado y avalado por los diferentes entes reguladores a nivel nacional e internacional. Lo anterior, sumado a un gran nivel de desinformación e incluso a una mala interpretación de la evidencia científica ha generado un aumento preocupante en el uso indiscriminado de medicamentos.

La ivermectina ha sido uno de los fármacos más apetecidos por la población, así mismo uno de los más probados y estudiados, una de las posibles causas de su gran acogida puede ser la escasa presencia de efectos adversos significativos. Esto ha llevado al medicamento a encontrarse en algunos protocolos en Europa Oriental, los cuales sugieren su uso en pacientes con enfermedad moderada a severa y evidencian una mejoría en términos de factor pronóstico como índices de oxigenación y requerimiento de FiO2 (10).

Finalmente, en cuanto a la dosis manejada en los diferentes ensayos que se encuentran en la literatura, aun no hay claridad: algunos reportan dosis entre $0.15-0.2 \mathrm{mg} / \mathrm{kg}$ (11), hasta dosis un poco más elevadas equivalentes a $300 \mu \mathrm{g} / \mathrm{kg}$ (12). Algunos autores consideran que estas dosis no alcanzan las concentraciones necesarias para generar un efecto similar al demostrado en los experimentos in-vitro de Caly et al (7), porque las concentraciones utilizadas en estos experimentos son cincuenta veces mayores a las que se consiguen con las dosis previamente descritas (14). Asimismo, el margen de seguridad de la invermectina en humanos oscila entre 100-120 mg (dosis única), por lo que se pone en gran duda su seguridad y eficacia a la hora de ser usada (15).

Como se evidencia, el uso de este medicamento es muy controversial entre la comunidad científica, algunos estudios han evidenciado ser favorecedores y otros no tanto. Sin embargo, es claro que en algunos países en los que se ha utilizado la ivermectina como tratamiento las tasas de mortalidad pueden dar una luz para salir de la incógnita respecto a su uso y a la seguridad del tratamiento en humanos.
Silvia Camila Amaya-Aponte, MD Médica, Especialista en Epidemiología(c) Universidad Autónoma de Bucaramanga Bucaramanga, Colombia

\section{Referencias}

1. Chan JFW, Yuan S, Kok KH, To KKW, Chu H, Yang $\mathrm{J}$, et al. A familial cluster of pneumonia associated with the 2019 novel coronavirus indicating person-toperson transmission: a study of a family cluster. Lancet [Internet]. 2020;395(10223):514-23. doi: http://dx.doi. org/10.1016/S0140-6736(20)30154-9

2. Meyerowitz EA, Richterman A, Gandhi RT, Sax PE. Transmission of SARS-CoV-2: A Review of Viral, Host, and Environmental Factors. Ann Intern Med [Internet]. 2021;174(1):69-79. doi: https://doi. org/10.7326/M20-5008

3. Zemkova H, Tvrdonova V, Bhattacharya A, Jindrichova M. Allosteric modulation of ligand gated ion channels by ivermectin. Vol. 63, Physiological Research. 2014. doi: https://doi.org/10.33549/physiolres.932711

4. Banerjee K, Nandy M, Dalai CK, Ahmed SN. The Battle against COVID 19 Pandemic: What we Need to Know Before we "Test Fire" Ivermectin. Drug Res (Stuttg). 2020;70(8):337-340. doi: https://doi. org/10.1055/a-1185-8913

5. Instituto Nacional de Vigilancia de Medicamentos y Alimentos - INVIMA. Sistema de Trámites en Línea - Consultas Públicas. 2017. :8082. Available from: http://consultaregistro.invima.gov.co:8082/Consultas/ consultas/consreg_encabcum.jsp

6. Schmith VD, Zhou J, Lohmer LRL. The Approved Dose of Ivermectin Alone is not the Ideal Dose for the Treatment of COVID-19. Clin Pharmacol Ther [Internet]. 2020;108(4):762-5. doi: https://doi. org/10.1002/cpt.1889

7. Caly L, Druce JD, Catton MG, Jans DA, Wagsta KM. The FDA-approved drug ivermectin inhibits the replication of SARS-CoV-2 in vitro. Antiviral Research 178, 104787. Antiviral Res [Internet]. 2020;178(January):104787. doi: https://doi.org/10.1016/j. antiviral.2020.104787

8. Rajter JC, Sherman MS, Fatteh N, Vogel F, Sacks J, Rajter JJ. ICON (Ivermectin in COvid Nineteen) study: Use of Ivermectin is Associated with Lower Mortality in Hospitalized Patients with COVID19. medRxiv [Internet]. 2020;(January). doi: https://doi. org/10.1101/2020.06.06.20124461

9. Ortega-Guillén E, Meneses G, Coila E. Remarks About Retrospective Analysis of Ivermectin Effectiveness on Coronavirus Disease 2019 (ICON Study). CHEST 
J [Internet]. 2020;159(1):2110-1. doi: https://doi. org/10.1016/j.chest.2020.10.088

10. Ahmed S, Karim MM, Ross AG, Hossain MS, Clemens JD, Sumiya MK, et al. A five-day course of ivermectin for the treatment of COVID-19 may reduce the duration of illness. Int J Infect Dis. 2021;103:214 6. doi: https://doi.org/10.1016/j.ijid.2020.11.191

11. Camprubí D, Almuedo-Riera A, Martí-Soler HI, Soriano A, Hurtado JC, Subirà C, et al. Lack of efficacy of standard doses of ivermectin in severe COVID-19 patients. PLoS One. 2020;15(11 November):1-6. doi: https://doi.org/10.1371/journal.pone.0242184

12. Behera P, Patro BK, Singh AK, Chandanshive PD, Ravikumar SR, Pradhan SK, et al. Role of ivermectin in the prevention of SARSCoV-2 infection among healthcare workers in India: A matched case-control study. PLoS One [Internet]. 2021;16(2 February):1-12. Available from: http://dx.doi.org/10.1371/journal. pone. 0247163
13. López-Medina E, López P, Hurtado IC, Dávalos DM, Ramirez O, Martínez E, et al. Effect of Ivermectin on Time to Resolution of Symptoms Among Adults With Mild COVID-19 A Randomized Clinical Trial Visual Abstract Supplemental content. JAMA [Internet]. 2021;325(14):1426-35. Available from: https:// jamanetwork.com/

14. Buonfrate D, Bisoffi Z. Standard Dose Ivermectin for COVID-19. Chest [Internet]. 2021;159(5):2111-2. doi: https://doi.org/10.1016/j.chest.2021.03.003

15. Zangrillo A. COVID-19y Argumentum ad ignorantiam o «no todo vale». Rev Clínica Española [Internet]. 2020;10(January):19-21. doi: https://doi.org/10.1016/j. rce.2020.04.013 